\title{
Topical Ocular Anesthetic Use among Welders of Rawalpindi City, Pakistan
}

\author{
Ume Sughra ${ }^{1}$, Wajid Ali Khan ${ }^{2}$ and Sultana Kausar ${ }^{1}$ \\ ${ }^{1}$ Department of Al-Shifa School of Public Health, Al-Shifa Research Centre, Pakistan Institute of Ophthalmology, Al-Shifa Trust Eye \\ Hospital, Rawalpindi, Pakistan \\ ${ }^{2}$ Department of Pakistan Institute of Ophthalmology, Cornea, Eye Bank, Al-Shifa Research Centre, Ethical Research Committee, Al-Shifa \\ Trust Eye Hospital, Rawalpindi, Pakistan
}

\begin{abstract}
A descriptive cross-sectional survey was done from January to June 2018 in welding shops of Rawalpindi city, Pakistan. The objectives of the study were to determine the frequency of topical ocular anesthetic use among welders and to assess the knowledge and practices of welders regarding safety measures. One hundred and fifty-eight welders from age group of 20 years and above, having welding work experience of more than one year, were included in the study. The sampling strategy was non-random convenient sampling. A pretested structured questionnaire was used to collect data.

Topical ocular anesthetic use among welders was found to be $45.6 \%$. Statistically significant association was found between knowledge and practices of welders regarding their safety measures $(p<0.05)$. On binary logistic regression, work experience was found to be the strongest predictor of good knowledge $(\mathrm{OR}=4.15,95 \% \mathrm{Cl}=1.45-12.15)$ and practices $(\mathrm{OR}=10.4695 \%$ $\mathrm{Cl}=2.92-37.51)$.
\end{abstract}

Key Words: Welder, Topical anesthetic abuse, Knowledge, Practices, Perceptions.

How to cite this article: Sughra U, Khan WA, Kausar S. Topical Ocular Anesthetic Use among Welders of Rawalpindi City, Pakistan. J Coll Physicians Surg Pak 2021; 31(06):737-739.

Welders and flame cutters are those who weld and cut metal parts using gas flame, electric arc and other sources of heat to melt and fuse metals. ${ }^{1}$ Welders are prone to occupational hazards, such as flying metal chips, burns in eyes, exposure to dangerousgases andultravioletradiations. An immediatetreatment taken by welders to these ocular problems is topical ocularanesthesia. ${ }^{2}$ Thistopicalanesthesia damages thesuperficial corneal epithelial microvilli by limiting the rate of corneal epithelial cell migration with direct toxic effects on stromal keratocytes. ${ }^{3}$ Globally, due to unintentional occupational injuries, more than 350,000 workers lose their lives each year. ${ }^{4}$ Flash burns are quite common in welders, but mistreatment may lead to serious deterioration of eye function.

A descriptive cross-sectional study was done on 158 welders between January to June 2018 in welding shops of Rawalpindi city, Pakistan. All welders from age group of 20 years and above, having welding work experience of more than one year, were included.

Correspondence to: Dr. Ume Sughra, Al-Shifa School of Public Health, Al-Shifa Research Centre, Pakistan Institute of Ophthalmology, Al-Shifa Trust Eye Hospital, Rawalpindi, Pakistan

E-mail:dr_sughra@yahoo.com

Received: August 25, 2020; Revised: December 29, 2020;

Accepted: February 16, 2021

DOI: https://doi.org/10.29271/jcpsp.2021.06.737
The sampling strategy was non-random convenient sampling. A sample size of 158 was calculated by using formula $z^{2} \mathrm{pq} / \mathrm{e}^{2}$, keeping $\mathrm{P}$ (Prevalence) $=80 \%,{ }^{5} 10 \%$ non-response rate within allowable error of $9 \%$. Data was collected by using a structured questionnaire after seeking formal permission from Ethical Review Committee (ERC-32/AST-18). Identification numbers were assigned to each questionnaire to ensure the confidentiality of the respondents. The Cronbach's alpha value for the tool came out to be 0.734 on reliability analysis. Content and construct validity of the tool was assessed by subject experts and through pilot testing. Data collection was done primarily by the principal researcher after taking informed verbal consent from each participant. Questions regarding demographics, knowledge and practices of personal protective equipment and topical ocular anesthesia use were asked and responses were marked on the questionnaire. Thestudy was conducted following the principles stated in Helsinki's Declaration. Descriptive as well as inferential statistics were applied for analysis of data, which was done by using SPSS version 17. The calculated total scores for practices were classified into two categories of poor $(\leq 19$ score), and good ( $\geq 20$ score); and for knowledge into poor ( $\leq 7)$ and good $(\geq 8)$ score based on their median score. Data was expressed as frequencies and percentages. Chi-square test of independence was applied to find out the associations between independent variables and dependent variables. Binary logistic regression was applied to determine the best predictor for knowledge and practices. A p-value $<0.05$ was considered statistically significant. 


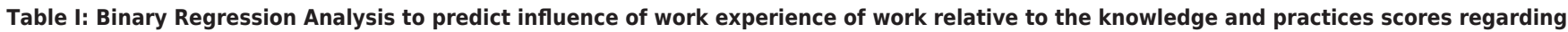
safety measures.

\begin{tabular}{|c|c|c|c|c|c|c|c|c|}
\hline \multirow{3}{*}{ Work experience } & \multicolumn{4}{|c|}{ Knowledge } & \multicolumn{4}{|c|}{ Practice } \\
\hline & \multirow{2}{*}{ Exp B } & \multicolumn{2}{|c|}{$95 \% \mathrm{Cl}$} & \multirow{2}{*}{ p-value } & \multirow{2}{*}{ Exp B } & \multicolumn{2}{|c|}{$95 \% \mathrm{Cl}$} & \multirow[t]{2}{*}{ p-value } \\
\hline & & Lower & Upper & & & Lower & Upper & \\
\hline $1-2$ & 4.15 & 1.45 & 12.15 & $<0.001$ & 10.45 & 2.92 & 37.51 & $<0.001$ \\
\hline $3-4$ & 1.10 & 0.24 & 5.13 & 0.905 & 2.083 & 0.53 & 8.14 & 0.292 \\
\hline $4-5$ & 1.95 & 0.46 & 8.28 & 0.368 & 2.857 & 0.67 & 12.20 & 0.156 \\
\hline Constant & 2.68 & & & 0.032 & 2.060 & & & 0.416 \\
\hline
\end{tabular}

Among 158 welders, 77 (48.7\%) were of age group 21-29 years and $53(33.5 \%)$ welders had primary schooling, and 92 $(58.2 \%)$ welders had more than five years of work experience.

Seventy-two welders (45.6\%) reported the use of topical ocular anesthetic. Sixty- one (38.6\%) reported availability of topical ocular anesthetic at shops.

A total of 70 welders (97.2) reported feeling of comfort after instilling local anesthetic in the eyes. Most common source of getting topical ocular anesthetic (54,75\%) among welders was pharmacies without prescription.

Of the 72 local ocular anesthetic users, 60 welders (83.3\%) reported use of topical ocular anesthetic to get relief from ocular discomfort. Most of the 41 users $(56.9 \%)$ reported no limit to the use of anesthetic and 49 (68.1\%) were unaware about its complications.

There was a statistically significant association of local ocular anesthetic use with education $(p=0.001)$ and injury to the eye ( $p$-value $<0.001)$. Respondents with low education level and had injury were more liable to the use of local anesthetic.

Fifty-eight respondents (37\%) reported the availability of first aid kit in their shops. Welders reporting injury to the eye in the past three months were $53(33.5 \%)$. One hundred and ten respondents (69.6\%) got spark and 119 (75.3\%) experienced irritation to the eye, while welding. One hundred forty-five $(91.8 \%)$ reported risk of getting spark, while working as helpers.

Ninety-five (60.1\%) and ninety-seven (61.4\%) respondents reported poor knowledge and practice regarding safety measures. There was significant association between knowledge and practices regarding safety measures among welders $(p<0.001)$.

A significant regression model was found $(p<0.001)$ indicating that the model was able to distinguish between respondents, who had good and poor knowledge regarding safety measures (Table I). This model was explained between $44.5 \%$ (Cox and Snell R square) and $60.2 \%$ (Negalkerker $\mathrm{R}$ square) of the variance between knowledge status and correctly classified $84.8 \%$ of cases. Only one of the independent variable made statistically significant contribution to the model (Work experience). Welders having work experi- ence of $1-2$ years were 4.15 times $(95 \% \mathrm{Cl}=1.45-12.15)$ more likely to have good knowledge regarding safety measures and 10.46 times $(95 \% \mathrm{Cl}=2.92-37.51)$ more likely to have good practices regarding safety measures as compared to welders with greater work experience. This result showed that with the increase in work experience, the knowledge and practices regarding safety measures get reduced.

Most welders reported purchasing the drops from pharmacies without prescription in this study and similar findings are reported by Karamouzian; et al. ${ }^{5}$ Many pharmacies have employees who prescribe medicines to the customers on the basis of symptoms, which is one of the reasons for misdiagnosis and inappropriate treatment. Due to the work nature and financial circumstances, welders usually seek quick relief of pain to resume their work quickly. Low level of education was found to be significantly associated with more frequent topical anesthetic use $(p<0.05)$. This finding is in contrast to a study which reported significance between high level of education and frequent use of anesthetics. ${ }^{5}$

More than half of the welders were using sunglasses at work other than recommended personal protective equipment (face-shield, goggles). ${ }^{1}$ The reason behind the use of sunglasses by the employers might be easy availability and low cost.

Age, education and work experience were significantly associated with knowledge and practices of safety measures in this study. Similar findings were found by Awosan et al, which showed significant relationship of level of education with awareness and use of PPE $(p<0.05){ }^{6}$

Health education and safety policies need to be strengthened at welding sectors to avoid self- medication. There is an intensive need to emphasise the ocular risks associated with the use of these medications.

\section{ETHICAL APPROVAL:}

Permission was taken from Ethical Research Committee of Al Shifa Trust Eye Hospital. Ethical Research Committee No. ERC-32/AST-18 was assigned.

\section{PATIENTS' CONSENT:}

Verbal Informed consents were taken from the patients.

\section{CONFLICT OF INTEREST:}

None to declare. 
AUTHORS' CONTRIBUTION:

US: Conception and design, literature search, manuscript writing, data analysis and interpretation.

WAK: Conception of idea, literature search, critical revision.

SK: Data acquisition, analysis and interpretation, manuscript drafting.

\section{REFERENCES}

1. ISCO - International Standard Classification of Occupations. Ilo.org. 2018 [cited 6 November 2018]. Available from: http://www.ilo.org/public/english/bureau/stat/isco

2. Sauder G, Jonas JB. Topical versus peribulbar anesthesia for cataract surgery. Acta Ophthalmol Scan 2003; 81(6): 596-9. doi: 10.1111/j.1395-3907.2003.00163.x.

3. Cox B, Durieux ME, Marcus MAE. Toxicity of local anes- thetics. Best Pract Res Clin Anaesthesiol 2003; 17(1): 111-36.

4. WHO. Global Health Risks: Mortality and burden of disease attributable to selected major risks. [Internet]. 2009. [cited7November 2018]. Available from: http://www.who. int/healthinfo/global_burden_disease/Global. Health Risks_ report_corrigenda 2009

5. Karamouzian M, Esmaeili H, Sharifi A, Sharifi H, Mokhtari M, Nejad A et al. Topical ocular anesthetic abuse among Iranian welders: Time for action. Middle East African J Ophthalmol 2013; 20(4):336. doi: 10.4103/0974-9233. 120023.

6. Awosan K, Makusidi M, Ibrahim M, Suleiman A, Magaji T, Mbatifuh F. Knowledge and safety practices related to exposure to physical and chemical hazards among welders in Sokoto, Nigeria. Asian J Med Health 2017; 9(1):1-11. 